\title{
Effects of Voltage Unbalance and Harmonics on Three-Phase PWM Ac-to-Dc Converters with Instantaneous Power Feedback
}

\author{
Non-member Wen-Inne Tsai \\ (National Cheng Kung University) \\ Non-member York-Yih Sun \\ (National Cheng Kung University) \\ Non-member Ming-Tsung Tsai \\ (Nan-Tai Junior College of Industrial and Commercial Management)
}

A PWM three-phase ac-to-dc converter with unity input power factor can be approached by setting the required active power and setting reactive power zero in the instantaneous reactive power theory. The instantaneous reactive power theory is proposed by Akagi and is usually used to design reactive power and harmonic compensators. In the power distribution system, voltage unbalance and harmonics always exist. The effects of the harmonics and voltage unbalance are presented and discussed in this paper. Moreover, a low pass filter is suggested to add into the coordinate transformation in the instantaneous reactive power theory to reduce the effects of harmonics and unbalance in the power source. Finally, the theoretical results are verified both by simulated and experimental results in a laboratory prototype system.

Keywords : Instantaneous reactive power, power factor, voltage unbalance

\section{Introduction}

Traditionally, conversion of ac line voltages from utilities has been done by a combination of a phasecontrolled rectifier and a bulk capacitor. Such a conversion approach leads to pulsed currents being drawn from the ac distribution networks. These currents contain an amount of harmonics, resulting in serious problems in the electric power system ${ }^{\prime \prime}$.

As a method of overcoming these problems, pulsewidth modulated ac-to-dc voltage source converters have been proposed. They have the merits of a nearly sinusoidal input current, a good power factor, and a regeneration ability. In the past, various control strategies have been proposed ${ }^{(2)-(6)}$, and some of them have been put into practice. Fig. 1 shows the main circuit of the three-phase PWM ac-to-dc converter, which consists a three-phase voltage source converter, three input inductors and a smoothing capactior in the dc side.

A control strategy which is based on the instantaneous reactive power theory and is suitable for three-phase PWM ac-to-dc converter is studied in this paper. The instantaneous reactive power theory, proposed by Akagi, is usually used to design the reactive power and harmonics compensators ${ }^{(7) 88}$. The basic idea of this control strategy is that if the power source only supplies the active power to the converter, then this converter will have a unity input power factor. Therefore, the current references of the three-phase ac-to-dc converter can be calculated, according to the instantaneous reactive power theory and the power demand of the converter. These current references are used to control the input inductor currents by three independent current regulators.

In the three-phase ac distribution network, voltage unbalance and harmonics typically exist. The effects of voltage unbalance and harmonics on the three-phase PWM ac-to-dc converter based-on the instantaneous reactive power theory are investigated. Moreover, a modified current reference calculator (MCRC) is proposed to reduce the effects of the non-ideal power source. To confirm the effectiveness of the proposed modified current reference calculator and the analytical results shown in this paper, some simulation and experimental results are presented. A test converter is made for the experiment.

\section{System configuration}

Fig. 2 shows the simplified functional block diagram of the proposed system. It mainly consists of a three- 


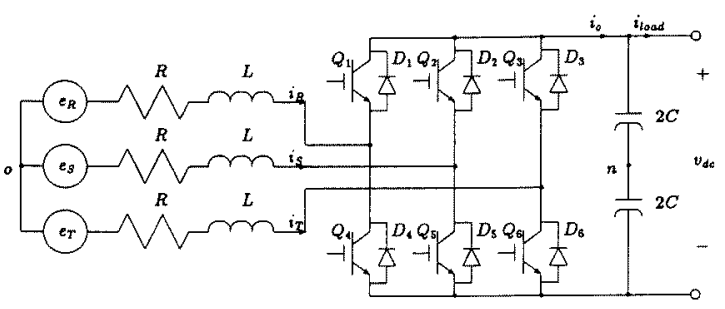

Fig. 1. Main circuit of the three-phase PWM ac-todc converter.

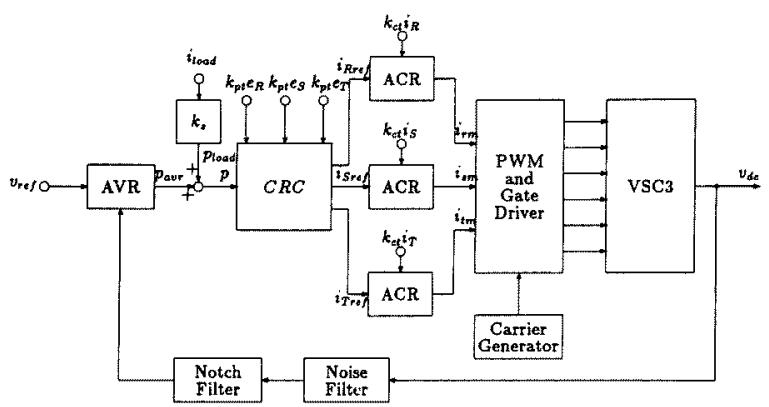

Fig. 2. Simplified functional block diagram of the three-phase PWM ac-to-dc converter with instantaneous power feedback.

phase voltage source converter (VSC3) whose main circuit is shown in Fig. 1, a notch filter and a noise filter, a carrier generator, a pulse width modulator (PWM), a voltage regulator (AVR), a current reference calculator (CRC) and three independent current regulators (ACR). The function of each control circuit shown in Fig. 2 will be described in more detail later on.

\subsection{Instantaneous Reactive Power Theory}

The instantaneous reactive power theory is briefiy reviewed as follows. According to the instantaneous reactive power theory, the instntaneous real (active) power $P_{L}$ and the instantaneous reactive power $q_{L}$ on the load side can be defined as follows. First, transformation of the instantaneous phase voltages $\left(\mathrm{e}_{R}, e_{S}\right.$, and $\left.e_{T}\right)$ of the power source and the line currents $\left(i_{R}, i_{s}\right.$, and $\left.i_{T}\right)$ into the $d-q$ orthogonal coordinates ( $e_{d}$ and $e_{q}, i_{d}$ and $i_{q}$ ) gives the following expressions:

$$
\begin{aligned}
& {\left[\begin{array}{l}
e_{d} \\
e_{q}
\end{array}\right]=\sqrt{\frac{2}{3}} C\left[\begin{array}{c}
e_{R} \\
e_{S} \\
e_{T}
\end{array}\right]} \\
& {\left[\begin{array}{c}
i_{d} \\
i_{q}
\end{array}\right]=\sqrt{\frac{2}{3}} C\left[\begin{array}{c}
i_{R} \\
i_{S} \\
i_{T}
\end{array}\right] \ldots}
\end{aligned}
$$

where $C$ is the coordinate transformation matrix and is given by

$$
C=\left[\begin{array}{ccc}
1 & -\frac{1}{2} & -\frac{1}{2} \\
0 & \frac{\sqrt{3}}{2} & -\frac{\sqrt{3}}{2}
\end{array}\right] .
$$

Then, the instantaneous real power $p_{L}$ and the instantaneous reactive power $q_{L}$ are defined by

$$
\left[\begin{array}{l}
p_{L} \\
q_{L}
\end{array}\right]=\left[\begin{array}{cc}
e_{d} & e_{q} \\
-e_{q} & e_{d}
\end{array}\right]\left[\begin{array}{l}
i_{d} \\
i_{q}
\end{array}\right]
$$

If the three-phase PWM ac-to-dc converter only draws the real power from the power source, the converter will have a unity input power factor. The current reference calculator is used to compute the desired input currents so as to achieve the operation condition.

\subsection{Current Reference Calculator}

In the current reference calculator (CRC), the three input phase voltages which are sensed by three star connecting potential transformers are converted into the $d \cdot q$ coordinates (denoted by $v_{d}, v_{q}$ ) by the coordinate transformation matrix :

$$
\left[\begin{array}{l}
v_{d} \\
v_{q}
\end{array}\right]=C\left[\begin{array}{l}
k_{p t} e_{R} \\
k_{p t} e_{S} \\
k_{p t} e_{T}
\end{array}\right]
$$

where $k_{p t}$ is the turn ratio of the potential transformer. Note that the scaling factor $\sqrt{2 / 3}$ is not used for ease of implementation because this will not affect the calculation in the CRC. Therefore, the current references can be given by the following expression from the instanta. neous reactive power theory.

$$
\begin{aligned}
& {\left[\begin{array}{c}
i_{\text {Rref }} \\
i_{\text {sref }} \\
i_{\text {rres }}
\end{array}\right]=\frac{1}{k_{m}} C^{T}\left[\begin{array}{cc}
v_{d} & v_{q} \\
-v_{q} & v_{d}
\end{array}\right]^{-1}\left[\begin{array}{l}
p \\
0
\end{array}\right]} \\
& =C^{T} \frac{p}{V_{d q}}\left[\begin{array}{l}
v_{d} \\
v_{q}
\end{array}\right]
\end{aligned}
$$

where $C^{T}$ denotes the transpose matrix of $C, V_{d q}$ denotes $k_{m}\left(v_{d}^{2}+v_{q}^{2}\right)$ and $p$ denotes the required power of the three-phase ac-to-dc converter which is the sum of the load power in the dc side and the power loss of the converter. The operations of multiplication and division in the CRC is performed by four analog multipliers and one analog divider, in which the gain of the multiplier is $k_{m}(=0.1)$ and the gain of the divider is $1 / k_{m}$. The control circuit picks up the load power $\left(p_{\text {load }}\right)$ by multiplying the load current $\left(i_{\text {load }}\right)$ by a scaling factor $k_{s}$ and the power loss of the converter is represented by the output of the voltage regulator $\left(p_{a v r}\right)$ as shown in Fig. 2. The input inductor currents can nearly track the current references by properly designing the current regulators (ACR). Therefore, the three-phase ac-to-dc converter has a unity input power factor.

\subsection{Current Regulator}

From the main circuit of the three-phase PWM ac-todc converter shown in Fig. 1, the dynamic equations of the input inductors can be expressed as 


$$
\begin{aligned}
& e_{R}=R i_{R}+L \frac{d i_{R}}{d t}+d_{1}^{*} \frac{v_{d c}}{2}+v_{n o} \\
& e_{S}=R i_{S}+L \frac{d i_{S}}{d t}+d_{2}^{*} \frac{v_{d c}}{2}+v_{n o} \\
& e_{T}=R i_{T}+L \frac{d i_{T}}{d t}+d_{3}^{*} \frac{v_{d c}}{2}+v_{n o}
\end{aligned}
$$

where

$d_{1}^{*}= \begin{cases}1 & \text { if } Q_{1} \text { or } D_{1} \text { ON, denoted SW } 1 \text { ON } \\ -1 & \text { if } Q_{4} \text { or } D_{4} \text { ON, denoted SW } 1 \text { OFF }\end{cases}$

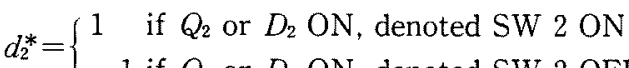

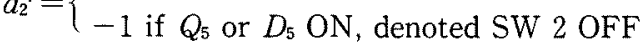

$d_{3}^{*}= \begin{cases}1 & \text { if } Q_{3} \text { or } D_{3} \mathrm{ON}, \text { denoted SW } 3 \text { ON } \\ -1 & \text { if } Q_{6} \text { or } D_{6} \mathrm{ON} \text {, denoted SW } 3 \text { OFF }\end{cases}$

For a three-phase system. without a neutral line, then

$$
i_{R}+i_{S}+i_{T}=0
$$

If the ac supply is a balanced source,

$$
e_{R}+e_{S}+e_{T}=0
$$

Thus, the voltage $v_{n o}$ can be obtained by adding Eqs. (6) $\sim(8)$ together:

$$
v_{n o}=-\frac{1}{6} v_{d c} \sum_{k=1}^{3} d_{k}^{*}
$$

The $\mathrm{ON}$ or OFF states of switches in Fig. 1 are determined by the pulse width modulator (PWM). If the modulating signal $\left(i_{r m}, i_{s m}\right.$, and $i_{t m}$ ) is smaller than the carrier, then $\mathrm{SW}_{k}$ is $\mathrm{ON}$, otherwise $\mathrm{OFF}$.

From equation (11), $v_{n o}$ is a coupled item and it will be considered as a disturbance in the current regulator design, since three independent current regulators are used. Therefore, the disturbance rejection of the current loop must be good enough to reduce the effects of $v_{n o}$.

\subsection{Voltage Regulator}

Assume that the input voltages are

$$
\left[\begin{array}{l}
e_{R} \\
e_{S} \\
e_{T}
\end{array}\right]=V\left[\begin{array}{c}
\sin (\omega t) \\
\sin \left(\omega t-\frac{2}{3} \pi\right) \\
\sin \left(\omega t+\frac{2}{3} \pi\right)
\end{array}\right]
$$

where $V$ is the peak value of the input voltage. Then, $v_{d}$ and $\mathrm{v}_{q}$ in the CRC can be expressed as

$$
\left[\begin{array}{l}
v_{d} \\
v_{q}
\end{array}\right]=\frac{3}{2} k_{p t} V\left[\begin{array}{l}
\sin (\omega t) \\
\cos (\omega t)
\end{array}\right]
$$

Substituting Eq. (13) into Eq. (5) gives the current references

$$
\left[\begin{array}{c}
i_{\text {Rref }} \\
i_{\text {sref }} \\
i_{\text {rref }}
\end{array}\right]=\frac{2}{3} \frac{p}{k_{p t} k_{m} V}\left[\begin{array}{c}
\sin (\omega t) \\
\sin \left(\omega t-\frac{2}{3} \pi\right) \\
\sin \left(\omega t+\frac{2}{3} \pi\right)
\end{array}\right] \cdots \cdots \cdots \cdots(14)
$$

Assume that the converter is lossless, that is, the switching and conducting loss of the switching elements and the loss of the reactive components are neglected. From the viewpoint of the power balance, the power of the $\mathrm{AC}$-side must be equal to the power in the $\mathrm{DC}$-side. $e_{R} i_{R}+e_{S} i_{S}+e_{T} i_{T}=v_{d c} i_{0}$

The inductor currents are controlled by three indepn. dent current regulators to track the current references from the $\mathrm{CRC}$. The relationship of the inductor currents and the current references are

$$
\left[\begin{array}{c}
i_{R} \\
i_{S} \\
i_{T}
\end{array}\right]=k_{a c r}\left[\begin{array}{c}
i_{\text {Rref }} \\
i_{\text {Sref }} \\
i_{\text {Tref }}
\end{array}\right]
$$

where $k_{a c r}$ is the closed-loop gain of the current loop in the line frequency $\omega$.

Substituting Eqs. (12) and (16) into Eq. (15) and considering the dynamic behavior of the smoothing capacitor, we have the system dynamic equations as follows.

$$
\begin{aligned}
& \frac{k_{a c r}}{k_{p t} k_{m}} p=v_{d c} i_{o} \\
& i_{o}=C \frac{d v_{d c}}{d t}+i_{\text {load }} \\
& p=p_{a v r}+k_{s} i_{\text {load }}
\end{aligned}
$$

where $i_{0}$ is the output current of the converter, $i_{\text {load }}$ is the load current, and $p_{a v r}$ is the output of the voltage regulator.

From Eqs. $(17) \sim(19)$, it is clear that the output dcbus voltage $\left(v_{d c}\right)$ is independent of the input source voltage. That means the output dc-bus voltage is not affected by the variations of the input source voltage, in other words, the converter has zero audio susceptibility.

For the derivation of the small signal model, let

$$
\begin{aligned}
& v_{d c}=V_{d c}+\hat{v}_{d c} \\
& i_{o}=I_{o}+i_{o} \cdots \ldots \ldots . \\
& p=P+\bar{p} \quad \cdots \ldots \ldots . \\
& p_{a v r}=P_{a v r}+\bar{p}_{a v r} \\
& i_{\text {load }}=I_{\text {load }}+\bar{i}_{\text {load }}
\end{aligned}
$$

where capitalized quantities refer to steady state values and carets indicate small perturbations. Substituting the above perturbed quantities into Eqs. (17) (19) and neglecting higher order terms, the small signal control block diagram can be get as shown in Fig. 3 and the corresponding parameters are given by

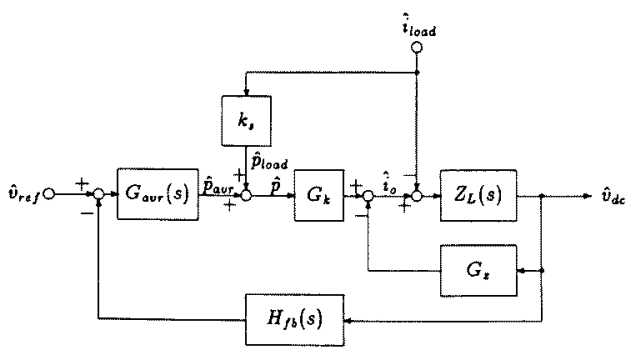

Fig. 3. Small signal model of the voltage loop. 


$$
\begin{aligned}
& Z_{L}(s)=\frac{1}{C_{S}} \\
& G_{z}=\frac{I_{o}}{V_{d c}} \\
& G_{k}=\frac{k_{a c r}}{k_{p t} k_{m} V_{d c}}
\end{aligned}
$$

In Fig. $3, G_{a v r}(s)$ is the voltage regulator and $H_{f b}(s)$ denotes the noise filter and notch filter. It is easy to show that if $k_{s}$ is chosen as

$$
k_{s}=G_{k}
$$

the perturbed output dc voltage will also not affected by the load changes.

The above derivations are based on the averaged small signal analysis, it shows the converter has a nearly perfect performance. In practice, the load change may be not in a small signal variation. This problem is well known to all approximate linearization techniques. Therefore, some experiments and simulation are needed to check the true behavior of this converter in large signal variations. However, small signal analysis will give useful information about this converter.

Based on this model, a simple PI compensator is designed in this work as a voltage regulator (AVR) to keep the output dc-bus voltage in the specified level and to have a fast transient response.

\section{Unbalanced power source}

Fig. 4(a) shows a typical three-phase ac supply system. Voltage unbalance and harmonic of the power source of the PWM ac-to-dc converter is caused by unbalanced loads and nonlinear loads in the same feeder.

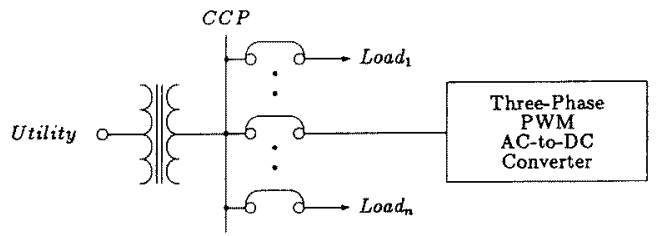

(a) Single wired diagram of a general ac distribution network.

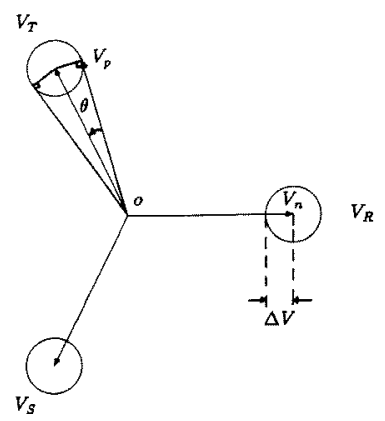

(b) Operating range in the terminal of the PWM ac-to-dc converter

Fig. 4. Voltage and phase unbalance in threephase voltage source.
Therefore, the range of the phase voltage at the common coupling point (CCP) corresponding to the rated current of the distribution transformer can be shown in Fig. 4 (b).

The voltage unbalance (VUB\%) is defined as $^{(9)}$

$$
(V U B \%)=100 \frac{V_{\max }-V_{\min }}{V_{\text {avg }}}
$$

where $V_{R}, V_{S}$ and $V_{T}$ are the peak values of the phase voltage, and

$$
\begin{aligned}
& V_{\mathrm{avg}}=\frac{V_{R}+V_{S}+V_{T}}{3} \\
& V_{\max }=\max \left(V_{R}, V_{S}, V_{T}\right) \\
& V_{\min }=\min \left(V_{R}, V_{S}, V_{T}\right)
\end{aligned}
$$

And the phase unbalance $(P U B)$ is defind $a^{(9)}$

$$
\begin{aligned}
P U B= & \max \left(\left|\phi_{R}-\phi_{S}-120^{\circ}\right|\right. \\
& \left.\left|\phi_{S}-\phi_{T}-120^{\circ}\right|,\left|\phi_{T}-\phi_{R}-120^{\circ}\right|\right)
\end{aligned}
$$

where $\phi_{R}, \phi_{s}$, and $\phi_{T}$ are the phase angles of the phase voltage. From Fig. 4 (b), one can find that the maximum voltage unbalance is

$$
(V U B \%)_{\max }=100 \frac{2 x}{1-\frac{x}{3}}
$$

and the maximum phase unbalance is

$$
(P U B)_{\max }=2 \theta \text {. }
$$

where $x$ denotes $\Delta V / V_{n}, V_{n}$ in the voltage at no load, $\Delta V$ is the maximum voltage drop in the line impedance at rated current, and $\theta=\sin ^{-1}(x)$. For example, if $x=$ $10 \%$, then the maximum voltage unbalance is $20 \%$ and the maximum phase unbalance is $11.5^{\circ}$.

Therefore, the instantaneous voltages of one of the maximum voltage unbalance and the maximum phase unbalance can be expressed in the following, respectively.

1. One case of maximum voltage unbalance :

$$
\left[\begin{array}{c}
e_{R} \\
e_{S} \\
e_{T}
\end{array}\right]=\left[\begin{array}{c}
\left(V_{n}-\Delta V\right) \sin \left(\omega_{t}\right) \\
\left(V_{n}-\Delta V\right) \sin \left(\omega t-120^{\circ}\right) \\
\left(V_{n}+\Delta V\right) \sin \left(\omega t+120^{\circ}\right) .
\end{array}\right] \cdots \cdots \cdots \cdots(30)
$$

2. One case of maximum phase unbalance:

$$
\left[\begin{array}{c}
e_{R} \\
e_{S} \\
e_{T}
\end{array}\right]=\left[\begin{array}{c}
V_{p} \sin (\omega t-\theta) \\
V_{p} \sin \left(\omega t-120^{\circ}+\theta\right) \\
V_{p} \sin \left(\omega_{t}+120^{\circ}+\theta\right)
\end{array}\right]
$$

where $V_{p}=V_{n} \sqrt{1-x^{2}}$

\section{Effects of harmonics and voltage unbalance}

The heart of the PWM converter is the CRC. The effects of the non-ideal power source containing the harmonics and unbalanced voltages on the $\mathrm{CRC}$ are investigated in this section. First, the CRC in the ideal power source is discussed for comparing with other cases. It is noted that the scaling factor in the practical 
hardware are omitted and the desired output power is constant in the following discussions.

\subsection{Ideal Power Source}

The sensed voltages in case of the ideal power source can be expressed as

$$
\left[\begin{array}{l}
v_{r n} \\
v_{s n} \\
v_{t n}
\end{array}\right]=V\left[\begin{array}{c}
\sin (\omega t) \\
\sin \left(\omega t-120^{\circ}\right) \\
\sin \left(\omega t+120^{\circ}\right)
\end{array}\right]
$$

where $V$ is the amplitude of the phase voltge. From (4), the parameters in the $\mathrm{CRC}$ can be given by

$$
\left[\begin{array}{l}
v_{d} \\
v_{q}
\end{array}\right]=\frac{3}{2} V\left[\begin{array}{c}
\sin (\omega t) \\
-\cos (\omega t)
\end{array}\right]
$$

and

$$
\begin{aligned}
V_{d q} & =v_{d}^{2}+v_{q}^{2} \\
& =\frac{9}{4} V^{2} \cdot
\end{aligned}
$$

If the desired output power is $P$, the reference currents become

$$
\left[\begin{array}{c}
i_{\text {Rref }} \\
i_{\text {sref }} \\
i_{\text {rref }}
\end{array}\right]=\frac{3}{2} P V^{-1}\left[\begin{array}{c}
\sin (\omega t) \\
\sin \left(\omega t-120^{\circ}\right) \\
\sin \left(\omega t+120^{\circ}\right)
\end{array}\right]
$$

Therefore, the three-phase PWM ac-to-dc converter has a unity power factor if the input currents exactly tracks the reference currents. From the above derivations, it is clear that $V_{d q}$ is a dc term if the power source is ideal.

\subsection{Harmonics}

The input voltages containing one balanced high frequency harmonic are given as

$$
\left[\begin{array}{l}
v_{m} \\
v_{s n} \\
v_{t n}
\end{array}\right]=V_{1}\left[\begin{array}{c}
\sin (\omega t) \\
\sin \left(\omega t-120^{\circ}\right) \\
\sin \left(\omega t+120^{\circ}\right)
\end{array}\right]+V_{2}\left[\begin{array}{c}
\sin (k(\omega t)) \\
\sin \left(k\left(\omega t-120^{\circ}\right)\right) \\
\sin \left(k\left(\omega t+120^{\circ}\right)\right)
\end{array}\right]
$$

According to $k$, three cases are discussed as follows.

1. Zero-phase sequence, i. e. $k=3,6,9, \cdots$

The parameters in the CRC are given by

$$
\left[\begin{array}{l}
v_{d} \\
v_{q}
\end{array}\right]=\frac{3}{2} V_{1}\left[\begin{array}{c}
\sin (\omega t) \\
-\cos (\omega t)
\end{array}\right]
$$

and

$$
V_{d q}=\frac{9}{4} V_{1}^{2}
$$

2. Positive-phase sequence, i. e. $k=4,7,10, \cdots$

The parameters in the $\mathrm{CRC}$ are given by

$$
\left[\begin{array}{l}
v_{d} \\
v_{q}
\end{array}\right]=\frac{3}{2} V_{1}\left[\begin{array}{c}
\sin (\omega t) \\
-\cos (\omega t)
\end{array}\right]+\frac{3}{2} V_{2}\left[\begin{array}{c}
\sin (k \omega t) \\
-\cos (k \omega t)
\end{array}\right]
$$

and

$$
V_{d q}=\frac{9}{4}\left(V_{1}^{2}+V_{2}^{2}\right)+\frac{9}{2} V_{1} V_{2} \cos ((k-1) \omega t) \cdots(40)
$$

3. Negative-phase sequence, i. e. $k=2,5,8, \cdots$ The parameters in the CRC are given by

$$
\left[\begin{array}{l}
v_{d} \\
v_{q}
\end{array}\right]=\frac{3}{2} V_{1}\left[\begin{array}{c}
\sin (\omega t) \\
-\cos (\omega t)
\end{array}\right]+\frac{3}{2} V_{2}\left[\begin{array}{c}
\sin (k \omega t) \\
\cos (k \omega t)
\end{array}\right]
$$

and

電学論D, 115 巻 1 号, 平成 7 年

$$
V_{d q}=\frac{9}{4}\left(V_{1}^{2}+V_{2}^{2}\right)+\frac{9}{2} V_{1} V_{2} \cos ((k+1) \omega t) \cdots(42)
$$

\subsection{Maximum voltage amplitude unbalance}

The voltages in the case of the maximum voltage amplitude unbalance can be expressed as

$$
\left[\begin{array}{l}
v_{m n} \\
v_{s n} \\
v_{t n}
\end{array}\right]=\left[\begin{array}{c}
(V-\Delta V) \sin (\omega t) \\
(V-\Delta V) \sin \left(\omega t-120^{\circ}\right) \\
(V+\Delta V) \sin \left(\omega t+120^{\circ}\right)
\end{array}\right]
$$

Then, the parameters in the CRC can be obtained as

$$
\begin{aligned}
{\left[\begin{array}{l}
v_{d} \\
v_{q}
\end{array}\right]=} & \frac{3}{2} V\left[\begin{array}{c}
\sin (\omega t) \\
-\cos (\omega t)
\end{array}\right] \\
& +\Delta V\left[\begin{array}{c}
-\sin (\omega t)-\frac{\sqrt{3}}{2} \cos (\omega t) \\
\frac{\sqrt{3}}{2} \sin (\omega t)
\end{array}\right]
\end{aligned}
$$

and

$$
\begin{aligned}
V_{d q}= & \frac{9}{4} V^{2}+\frac{5}{4}(\Delta V)^{2}-\frac{3}{2} \Delta V V \\
& -\frac{1}{2}\left((\Delta V)^{2}-\frac{3}{2} \Delta V V\right) \cos (2 \omega t) \\
& +\frac{\sqrt{3}}{8}\left(4(\Delta V)^{2}-9 \Delta V V\right) \sin (2 \omega t) .
\end{aligned}
$$

\subsection{Maximum phase unbalance}

The voltages in the case of the maximum phase unbalance may be expressed as

$$
\left[\begin{array}{c}
v_{m} \\
v_{s n} \\
v_{t n}
\end{array}\right]=\left[\begin{array}{c}
V \sin (\omega t-\theta) \\
V \sin \left(\omega t-120^{\circ}+\theta\right) \\
V \sin \left(\omega t+120^{\circ}+\theta\right)
\end{array}\right]
$$

Then, the parameters in the CRC can be obtained as

$$
\begin{aligned}
{\left[\begin{array}{c}
v_{d} \\
v_{q}
\end{array}\right]=} & \frac{3}{2} V \cos (\theta)\left[\begin{array}{c}
\sin (\omega t) \\
-\cos (\omega t)
\end{array}\right] \\
& +\frac{3}{2} V \sin (\theta)\left[\begin{array}{c}
-\frac{1}{3} \cos (\omega t) \\
\sin (\omega t)
\end{array}\right]
\end{aligned}
$$

and

$$
\begin{aligned}
V_{d q}= & V^{2}\left(\frac{9}{4} \cos ^{2}(\theta)+\frac{5}{4} \sin ^{2}(\theta)\right. \\
& -\cos (2 \omega t)-\frac{3}{2} \sin (2 \theta) \sin (2 \omega t)
\end{aligned}
$$

\subsection{Modified CRC}

From the above derivations, if the power source is non-ideal then $V_{d q}$ contains undesired components. These will contaminate the reference current generated by the $\mathrm{CRC}$. For the maximum voltage unbalance and the maximum phase unbalance, from Eqs. $(43) \sim(48)$, these equations can be expressed in a general form as

$$
\begin{aligned}
& V_{d g}=V_{d c}\left(1-k_{1} \sin (2 \omega t+\alpha)\right) \\
& v_{d}=k_{2} \sin (\omega t+\beta) \quad \cdots \ldots \ldots \ldots \ldots \ldots \ldots \ldots \ldots \ldots \ldots \\
& v_{q}=k_{3} \sin (\omega t+\gamma)
\end{aligned}
$$

where

$$
k_{1}<1
$$

Then, 




(a) Block diagram.



(b) Circuit.

Fig. 5. Modified coordinate transformation.

$$
\begin{aligned}
V_{d q}^{-1} & =V_{d c}^{-1}\left(1+k_{1} \sin (2 \omega t)+k_{1}^{2} \sin ^{2}(2 \omega t)+\cdots\right. \\
& \cong V_{d c}^{-1}\left(1+k_{1} \sin (2 \omega t)\right) \quad \cdots \cdots \cdots \cdots \cdots \cdots \cdots \cdots
\end{aligned}
$$

Therefore,

$$
\begin{aligned}
& {\left[\begin{array}{c}
i_{\text {Rref }} \\
i_{\text {sref }} \\
i_{\text {Tref }}
\end{array}\right]=C^{T} \frac{p}{V_{d c}}\left[\begin{array}{l}
k_{2} \sin (\omega t+\beta)+\frac{k_{1} k_{2}}{2} \sin (\omega t+\alpha-\beta) \\
k_{3} \sin (\omega t+\gamma)+\frac{k_{1} k_{3}}{2} \sin (\omega t+\alpha-\gamma)
\end{array}\right.} \\
& \left.\begin{array}{l}
-\frac{k_{1} k_{2}}{2} \sin (3 \omega t+\alpha+\beta) \\
-\frac{k_{1} k_{3}}{2} \sin (3 \omega t+\alpha+\gamma)
\end{array}\right]
\end{aligned}
$$

From the above derivation, the current references contain third harmonics and their amplitude is proportional to the component with frequency of $2 \omega$ in $V_{d q}$.

A modified CRC, shown in Fig. 5, is proposed in this paper to reduce the effects of voltage unbalance and harmonics. This is done by adding a low pass filter into the $\mathrm{CRC}$ to filter out the components with frequency greater than $2 \omega$ in $V_{d q}$. The circuit of the MCRC is shown in Fig. 5 (b).

\section{Simulation and experimental results}

For verification, a laboratory prototype three-phase PWM ac-to-dc converter system is setup. An input threephase transformer is used to match the utility voltage and the designed input voltage, and a three-phase input filter is used to eliminate the high frequency components in the inductor currents. Three $50 \mathrm{~A} 600 \mathrm{~V}$ IGBT modules are used as switching elements. Five analog multipliers are used to perform the operations in the CRC.

\subsection{System parameters}

The parameters used in this three-phase PWM ac-todc converter are

1. the source phase voltage is $80 \mathrm{~V}$;

2. the dc output voltage is $240 \mathrm{~V}$;

3. the load resistor is $10.8 \Omega$;

4. the inductance of the input inductor is $1 \mathrm{mH}$;

5. the switching frequency is $11 \mathrm{kHz}$;

6. the capacitance of the smoothing capacitor is 7200 $\mu \mathrm{F}$.

Fig. 6 shows the measured waveforms in the balanced 


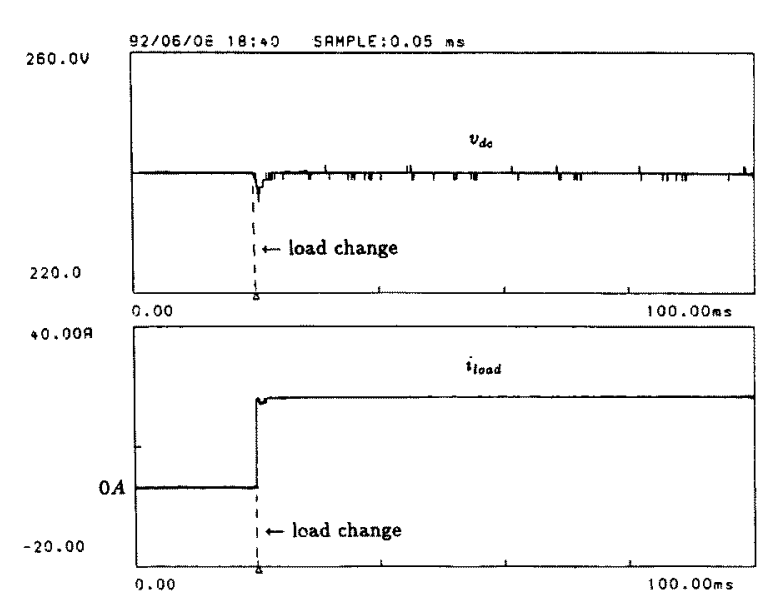

(a) Transient of output voltage and load current.

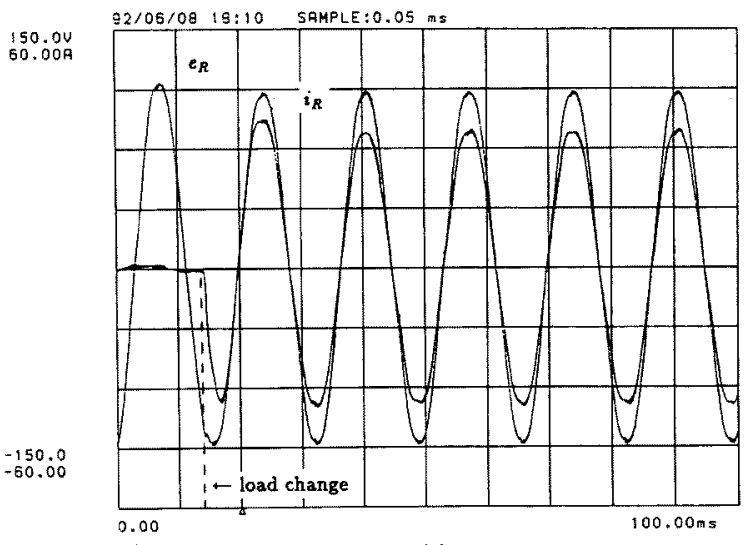

(b) Input phase voltage and input current.

Fig. 6. Experimental waveforms in the balanced power source.

power source. Fig. 6 (a) shows the transient response of the output voltage at no-load to full-load and Fig. 6(b) shows the corresponding input current and phase voltage. From Fig. 6, it shows the converter has a unity power factor and a nearly perfect voltage dynamic regulation.

\subsection{Simulation results}

The proposed three-phase PWM ac-to-dc converter system including a power electronic stage and a control stage is simulated by the PC based SIMNON program ${ }^{(10)}$. Fig. 7 and Fig. 8 show the simulation results of the maximum voltage amplitude unbalance and maximum phase unbalance with $x=10 \%$, respectively. $V_{d q}$ in the unbalanced power source contains second order harmonics which lead to the distorted input current.

For demonstrating the design of the LPF in the MCRC, three Butterworth low pass filters (BLPF) are illustrated.

1. Second-order BLPF with cutoff frequency $=34$ $\mathrm{Hz}$ : $-20 \mathrm{~dB}$ for $120 \mathrm{~Hz}$;

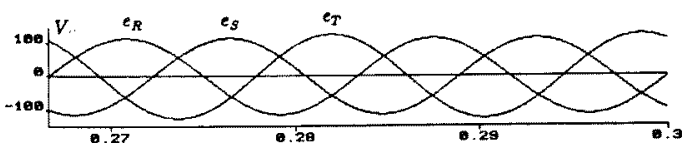

(a) Waveforms of input phase voltages.

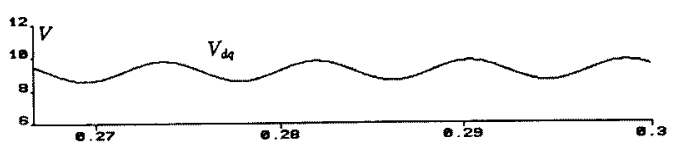

(b) Waveform of $V_{d q}$.

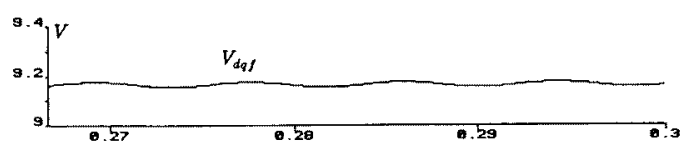

(c) Waveform of $V_{d q f}$

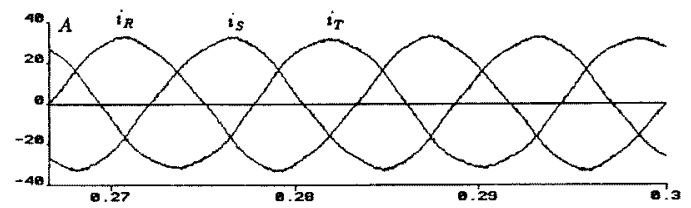

(d) Waveforms of input currents, in the $\mathrm{CRC}$.

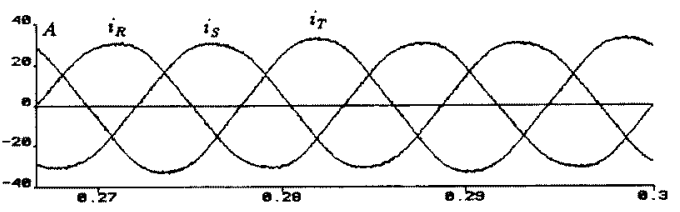

(e) Waveforms of input currents, in the MCRC.

Fig. 7. SIMNON simulation results in case of the maximum voltage amplitude unbalance.

2. Second-order BLPF with cutoff frequency $=12$ $\mathrm{Hz}$ : $-40 \mathrm{~dB}$ for $120 \mathrm{~Hz}$;

3. Fourth-order BLPF with cutoff frequency $=34$ $\mathrm{Hz}$ : $-40 \mathrm{~dB}$ for $120 \mathrm{~Hz}$.

The input current total harmonic distortion (THD) and the ripple factor of the output voltage are chosen to evaluate the effects of the BLPF, and the results are shown in Fig. 9 (a) for the ripple factor and Fig. 9(b) for the current THD respectively. From Fig. 9, it shows the case (2) and case ( 3 ) have nearly same results and the case (2) and case (3) are slightly better than the case (1) in the current THD of the input currents and the ripple factor of the output voltage. That means the design of LPF in the MCRC does not strongly affect the three-phase current waveforms $i_{R}, i_{S}$ and $\mathrm{i}_{T}$.

The PLL method, which is possible to obtain balanced and purely sinusoidal three-phase current reference signals by introducing a phase-lock-loop circuit even if three-phase voltages are unbalanced, and the CRC method are also evaluated and are shown in Fig. 9. From Fig. 9, we can find three facts:

1. The ripple factor of the CRC method is the smallest. 


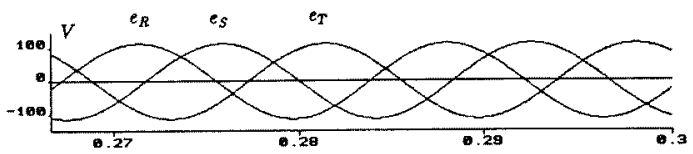

(a) Waveforms of input phase voltages.



(b) Waveform of $V_{d q}$

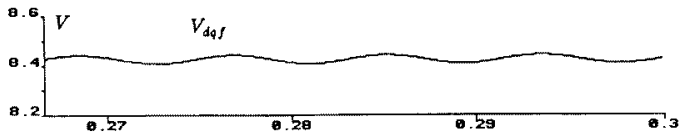

(c) Waveform of $V_{d \Psi}$,

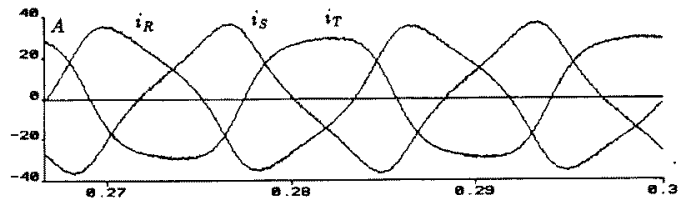

(d) Waveforms of input currents, in the CRC.

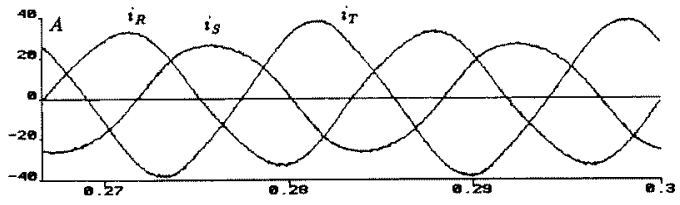

(e) Waveforms of input currents, in the MCRC.

Fig. 8. SIMNON simulation results in case of the maximum phase unbalance.

2. The current THD of the CRC method is the largest.

3. The voltage ripple and the current THD of the PLL method are smaller than the ones of the MCRC method.

These facts can be explained in the following. Since the current references in the $\mathrm{CRC}$ are based on the instantaneous reactive power theory, the ripple in the output voltage is zero theoretically even if the voltage source is unbalanced. However, the input currents will be distorted. The input current THD of the MCRC is greatly improved but the ripple factor becomes higher because the phase differences exist between the current references and the input voltages. This can be seen in Eq. (53). The PLL method is better than the MCRC method in the voltage ripple, but it losses the feedforward compensation of the input line voltages. Consider ing the feedforward compensation of the input line voltages, the MCRC having a second-order BLPF with cutoff frequency $=34 \mathrm{~Hz}$ is chosen in experiments.

\subsection{Experimental results}

To demonstrate the effects of the modified CRC, a single-phase auto-transformer (about $3 \mathrm{kVA}$ ) is used to

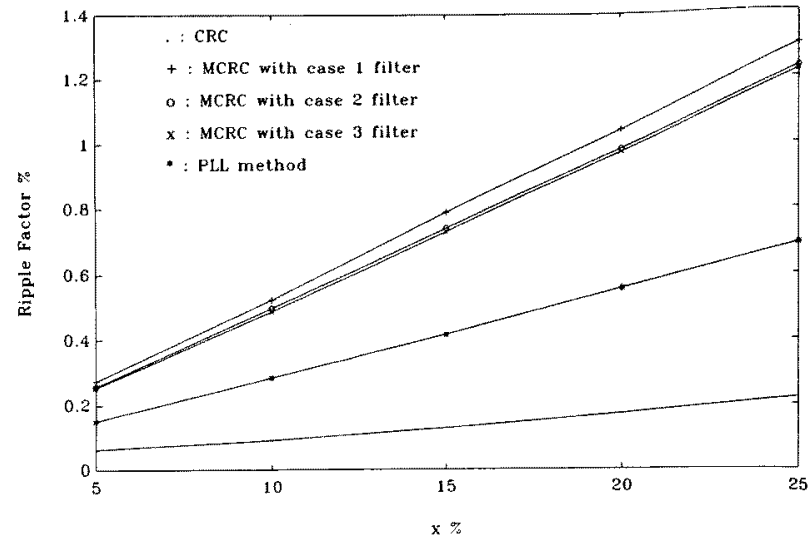

(a) Ripple factor of the output dc voltage.

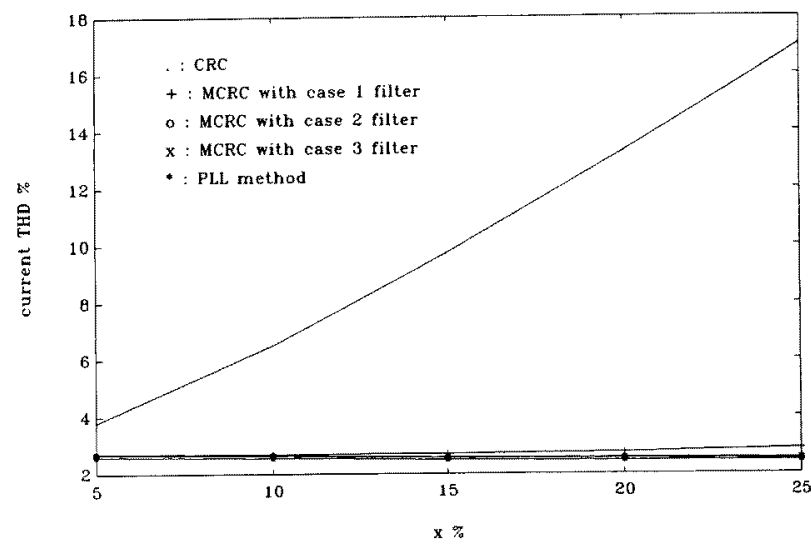

(b) Total harmonic distortion of the input current.

Fig. 9. Comparison of the CRC, MCRC and PLL methods.

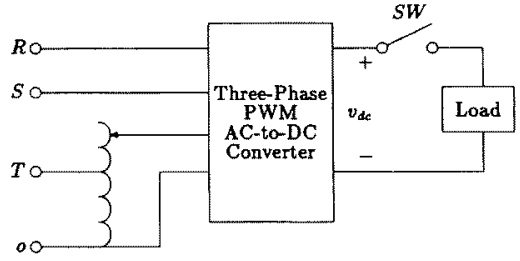

Fig. 10. Scheme of the experimental equipment.

adjust the amplitude of the phase- $T$ voltage to the desired voltage unbalance and the setup of this experiment is shown in Fig. 10. Here, the phase-T voltage is increased to $110 \%$. The input phase-voltages in this experiment are slightly contaminated by harmonics. The spectrums of the input phase-voltages are measured and the averaged THD is $2.6 \%$. Fig. 11 (a) shows the waveform of $V_{d q}$ and its spectrum. It shows that $V_{d q}$ contains an amount of second order harmonic, this is agreed with the analytic results. Fig. 11 (b) and Fig. 11 (c) show the experimental waveforms of the input inductor currents with the $\mathrm{CRC}$ and with the MCRC, respectively. The measured averaged THD of the input 


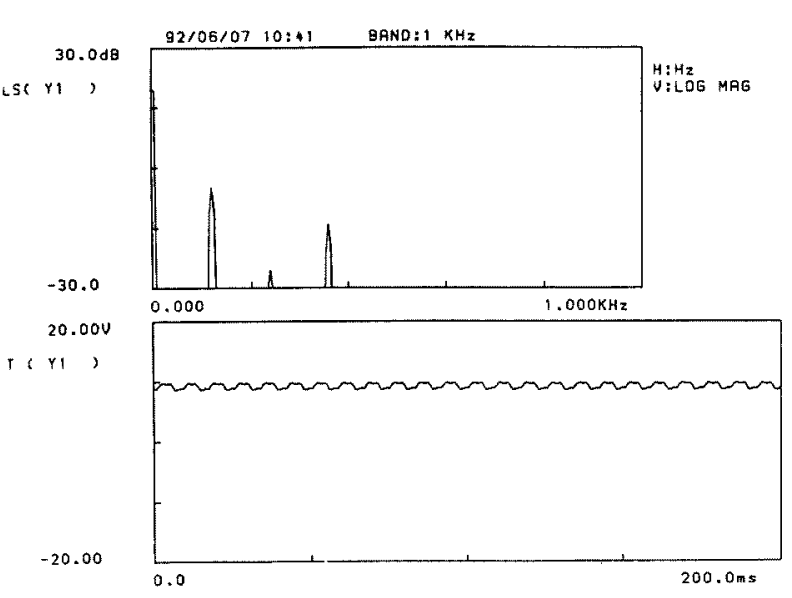

(a) Waveforms of $V_{d q}$ and its spectrum.

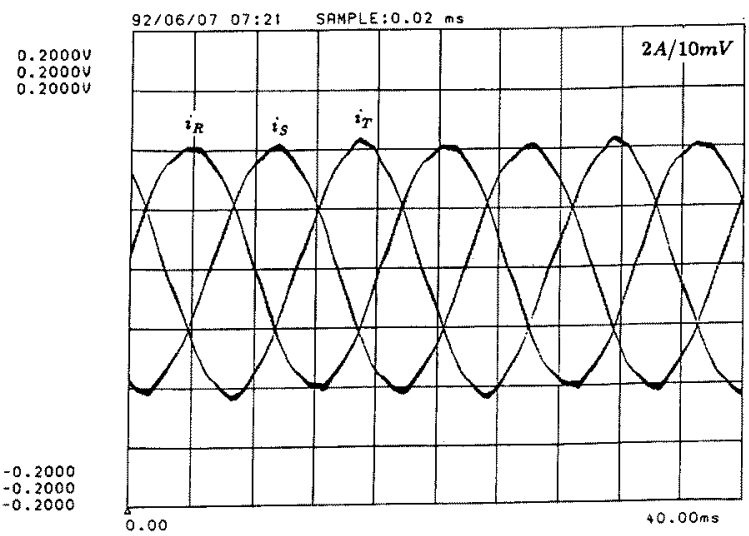

(b) Waveforms of input currents, in the CRC.

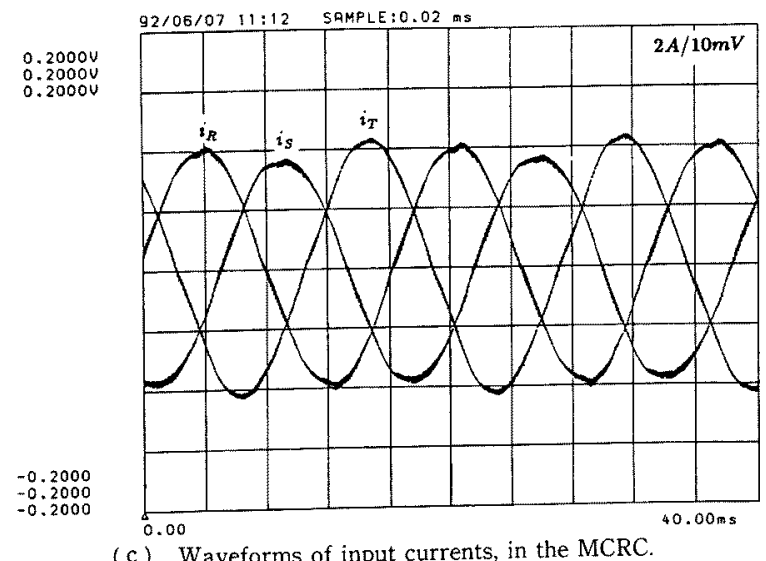

(c) Waveforms of input currents, in the MCRC

Fig. 11. Experimental results in the unbalanced power source.

currents is $3.96 \%$ when the modified CRC is used and is $5.05 \%$ for the CRC.

\section{Conclusions}

In this paper, effects of non-ideal power source on a three-phase PWM ac-to-dc converter based on the instantaneous reactive power theory has been presented.
Moreover, a modified current reference calculator was proposed to reduce the effects.

A brief conclusions of this paper are given in the following.

1. The three-phase PWM ac-to-dc convemter with instantaneous power feedback has a nearly perfect dynamic voltage regulation.

2. Harmonics will appear in the current references if the power source of the converter is unbalanced or contains harmonics.

3. The effects of voltage unbalance and harmonics can be compensated by a low pass filter which completely attenuates $2 \omega$ components or higher ones.

4. Both simulation and experimental results are presented and these are agreed with the analytic ones.

\section{Acknowledgment}

The authors acknowledge the financial support of this work by the National Science Council of R. O. C. under Contract No. NSC81-0404-E006-024. The authors also express their gratitude to Lumen Electronic Corp., Taiwan, for their assistance in experiment

(Manuscript received March 31, '94, revised September 29, '94)

\section{References}

(1) D. Gauger, T. Froeschle \& L. Illingworth: “A three-phase off-line switching power supply with unity power factor and low TIF," in Conf. Rec. 1986 IEEE-PECS, pp. 115-121

(2) A. B. Kulkarni, J. W. Dixon, M. Nishimoto \& B. T. Ooi : "Transient tests on a voltageregulated controlled-current PWM converter," IEEE Trans. Ind. Elec., Vol.IE-34, No. 3, pp. 319-324, (Aug. 1987)

(3) A. W. Green \& J. T. Boys: "Hysteresis current-forced three phase voltfge-sourced reversible rectifier," IEEE Proc. Pt. B, Vol.136, No. 3, pp. 113-120, (May 1989)

(4) J.W. Dixon \& B. T. Ooi: "Indirect current control of a unity power factor sinusoidal current boost type three-phase rectifier," IEEE Trans. Ind. Eleciron. Vol.35, No.3, pp. 508 515, (Nov. 1988)

(5) M. Sugimoto, S. Morimoto \& Tano: "A high performance control method of a voltagetype PWM converter," in Conf. Rec. 1988 IEEE-PESC, pp. 366-368

(6) R. Wu, S. B. Dewan \& G. R. Selmon: "A PWM Ac-to-Dc converter with fixed switching frequency," IEEE Trans. Ind. Appl., Vol.26, No. 5, pp. 880-885, (Sep./Oct. 1990)

(7) H. Akagi, Y. Kanazawa \& A. Nabae: "Instantaneous reactive power compensators comprising switching devices without energy storage components," IEEE Trans. Ind Appl., Vol. IA.20, No. 3, pp.625-630, (May/June 1984)

(8) F. Z Peng, H. Akagi \& A. Nabae: "A study of active power filters using quad-series voltage-source PWM converters for harmonic compensator", IEEE Trans. Power Electronics, Vol. PE-5, No. 1, pp. 110-112, (Aug. 1986)

(9) Y. Miguchi, A. Kawamura \& R. Hoft: "Decoupling servocontrol of three-phase PWM inverter for UPS application," in IEEE IAS Ann. Mtg., pp. 724-733 (1987)

(10) SIMNON.User's Guide for MS ${ }^{\mathrm{TM}}$.DOS Computers, Depart ment of Automatic Control Lund Institute of Technology, Lund, Sweden, 1988 
Wen-Inne Tsai (Non-member) $\mathrm{He}$ was born in Tainan,


Taiwan, 1963. He graduated from the Department of Electrical Engineering of National Institute of Technology (NKIT) in 1984 and received the M.S. degree in electrical engineering from National Cheng Kung University (NCKU) in 1989. Since 1989 he has been working towards the $\mathrm{Ph}$. D. degree in electrical engineering at NCKU. Currently, his research interests include modelling and control of power electronic systems, soft switched power converters, active power filters and the advanced motion control.

York-Yih Sun (Non-member) He was born in Amoy, Fu-

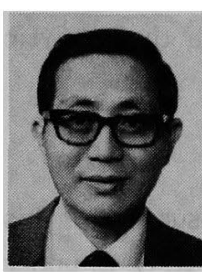
kien Province, China, 1933. He received the B. S. E. E. degree from the National Cheng Kung University, Taiwan, Republic of China, in 1957, and the M. S.E.E. degree from Purdue University, Lafayette, IN, in 1968 . He is presently a Professor in the Electrical Engineering Department, National Cheng Kung University where he has been teaching for 32 years. His current interests are in power electronics, digital control and adaptive signal process ing.
Wing-Tsung Tsai (Non-member) He was born in Tainan,

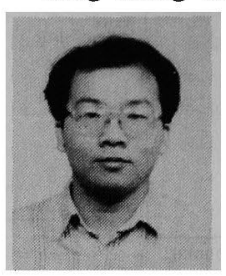
Taiwan, 1964. He graduated from the Department of Electrical Engineering of National Institute of Technology (NKIT) in 1984 and received the $M$. S. degree in electrical engineering from National Cheng Kung University (NCKU) in 1991. He is presently a lecturer in the Electrical Engineering Department, NanTai Junior College of Industrial and Commercial Management. Currently, his research interests include active power filter, battery energy storage system, and residential photovoltaic power conditional system. 